\title{
PAH structure analysis of soot in a non-premixed flame using High-Resolution Transmission Electron Microscopy and Optical Band Gap Analysis
}

\author{
Maria L. Botero ${ }^{\mathrm{a}}$, Erin M. Adkins ${ }^{\mathrm{b}}$, Silvia González-Calera ${ }^{\mathrm{a}}$, Houston \\ Miller $^{\mathrm{b}}$, Markus Kraft ${ }^{\mathrm{a}, \mathrm{c}, *}$ \\ ${ }^{a}$ University of Cambridge, Chemical Engineering 83 Biotechnology, New Museums Site, \\ Pembroke Street, Cambridge, CB2 3RA, United Kingdom \\ ${ }^{b}$ George Washington University, Department of Chemistry, Corcoran Hall 725 21st St. \\ NW, Washington, DC 20052, USA \\ ${ }^{c}$ Nanyang Technological University, School of Chemical and Biomedical Engineering, 62 \\ Nanyang Drive, 637459, Singapore
}

\begin{abstract}
Soot particles formed in a system of non-premixed liquid fuel flames supported on a wick-fed, smoke point test burner (ASTM D1322-08) were characterised by in-situ visible light extinction and thermophoretically-sampled high-resolution transmission electron microscopy measurements, HRTEM. The fuels studied were heptane, toluene and their iso-volumetric mixture (H50T50), given their relevance as surrogate fuels. Extinction measurements were used to calculate the soot volume fraction, $F_{v}$, and determine the optical band gap (OBG) as a function of flame position. The OBG was derived from the near-edge absorption feature using Tauc/Davis-Mott analysis. A direct band gap $(r=0.5)$ was selected for this analysis assuming that the electronic properties of soot are dominated by the molecular structure of the PAHs.
\end{abstract}

\footnotetext{
${ }^{*}$ Corresponding Author

Email address: mk306@cam.ac.uk (Markus Kraft)
}

Preprint submitted to Combustion and Flame

November 18, 2015

(c) 2015. This manuscript version is made available under the Elsevier user license http://www.elsevier.com/open-access/userlicense/1.0/ 
For the HRTEM analysis, soot samples were collected at different locations in the flame using thermophoretic sampling and a fast-insertion technique. The images were then analysed using a 'lattice-fringe' algorithm, to determine important parameters such as the fringe length. Polycyclic aromatic hydrocarbon $(\mathrm{PAH})$ sizes were estimated from conjugation lengths obtained from OBG measurements and fringe lengths from HRTEM measurements. Across all studied flames, the peak $F_{v}$ ranged from $3.4 \mathrm{ppm}$ in the heptane flame to $17.6 \mathrm{ppm}$ in the toluene flame. Despite this wide range, the average OBG across the different flames only varied from $2.05 \mathrm{eV}$ in the H50T50 to $2.10 \mathrm{eV}$ in the toluene flames, which is consistent with molecule lengths of between $0.96 \mathrm{~nm}$ and $0.99 \mathrm{~nm}$. Lattice fringe analysis yielded slightly lower average fringe lengths between $0.91-0.99 \mathrm{~nm}$ throughout the different flames. Results of in-situ and ex-situ characterization of soot suggests that flames of different fuel nature and sooting stage undergo the transition from chemical to physical growth at a similar size, about the size of circumpyrene.

Keywords: soot, laser extinction, optical band gap, HRTEM, lattice-fringe analysis

\section{Introduction}

The high complexity of petroleum-based fuels has encouraged the search for mixtures of limited components to ease the development of new combustion technologies through computational tools, and to generate insight and understanding of underlying fundamental processes. Commercial fuels are mixtures of hundreds of hydrocarbons. The primary chemical classes of hydrocarbons in fuels are paraffins, olefins and aromatics $[1,2]$. The soot 
particles formed by the combustion of these fuels are widely regarded as pollutants, and are increasingly regulated both in terms of number and mass of particulate matter emitted from on-road vehicles.

Sooting limits are defined to assess the sooting propensity of a fuel. In co-flow diffusion flames a common target is the smoke point - the greatest flame height without smoke emission under laminar diffusion combustion [3]. A lower smoke point indicates a higher sooting tendency. In 1950's the first studies trying to relate the molecular structure of hydrocarbons with smoke point were published $[4,5]$. The results indicated that the rate at which hydrocarbons produced soot increased as follows: paraffins < isoparaffins $<$ mono-olefins $<$ naphthenes $<$ alkynes $<$ aromatics. Comparing molecules with the same number of carbons, the more compact the structure, the greater the tendency to soot. Further, several studies have observed that a high percentage of fuel carbon in aromatic structures is converted into soot [6]. Therefore branched or cyclic structures present lower smoke points, although the effect is small compared with the increase in sooting tendency derived from the increase of aromatic character [7].

The formation of soot during combustion has been the subject of extensive research. The last century has seen significant efforts to explain model, and predict the hundreds of chemical and physical changes that take place in combustion processes $[8,9,10,11,12,13,14,15]$. A widely accepted interpretation is that the pathway begins with the formation of molecular precursors such as polyacetylenes and polycyclic aromatic hydrocarbons (PAHs) from the fuel source [10]. There is some agreement that the rate limiting reaction is the formation of the first aromatic ring, for which various mechanisms 
have been proposed $[16,17]$. The mechanism for particle inception is debated, but there is significant proof suggesting PAHs play an important role $[18,19]$. As the molecular mass of PAHs increases a collision between two such molecules becomes more likely to result in the formation of a dimer [10]. Therefore polymerisation occurs at an increasing rate, forming larger molecules until the inception of a solid nucleus occurs. Another model for particle inception states that changes in temperature and pressure along the space result in condensation of PAHs, followed by formation of liquid nuclei, which then proceed to form solid particles [10, 17]. Once primary particles are formed, these nascent soot particles undergo surface growth (and in some systems, competing oxidation reactions), and the small particles agglomerate into larger fractal structures [8, 10, 20].

Experimental studies of soot morphology revealed that the crystallinity in mature soot particles arises due to stacking of planar PAHs to form parallel atomic layers and their alignment along the periphery of soot particles $[21,22,23,24]$. It is clear from these studies that PAH molecules act as a soot precursor, and their relative orientations reveals the degree of crystallinity of soot particles. The variations in the structure of the PAHs, their sizes and their orientations in soot particles has also been found to depend heavily on the type of the fuel producing it, fuel flow rate and the temperature $[25,26]$. The presence of PAH stacks and clusters revealed by HRTEM images of soot particles, indicates that the coagulation of PAHs may be responsible for soot nucleation. Furthermore, through Raman spectroscopy, crystallite sizes between 1.0-1.2 nm were estimated in a diffusion flame, corresponding to PAHs with 4-5 aromatic rings across (approximately the size 
of circumcoronene) [27].

In soot models it is often assumed that pyrene dimerization is the critical soot particle formation step [28, 29]. However, there are a number of recent studies that challenge this view [16, 30, 31, 32, 33]. For example, the PAH growth mechanism presented by Violi [34] models large, non-planar PAH sheets in a flame-like environment. A large set of reactions describe the growth of a PAH molecule using a kinetic Monte Carlo (KMC) algorithm and Molecular dynamics (MD) techniques. They found that molecular size was the largest factor with the onset of dimerization possibly beginning with PAHs the size of ovalene $\left(\mathrm{C}_{38} \mathrm{H}_{14}\right)$ [34, 35]. Similar results were found by Kraft's group at Cambridge employing a population balance PAH-PP (polyaromatic hydrocarbon-primary particle) model [36, 37, 38] coupled with KMC-ARS (kinetic Monte-Carlo-aromatic site). For the physical binding of PAHs based on van der Waals interactions large PAH molecules of the order of 50 carbon atoms were found to be required [36, 39]. Using conventional molecular dynamics (MD) simulations with the isoPAHAP potential (isotropic potential for the PAH interactions), the melting points of clusters of ovalene, hexabenzocoronene and circumcoronene were estimated. It was concluded that at $1500 \mathrm{~K}$ a critical size of peri-condensed PAH for a nascent soot particle is $\mathrm{C}_{71} \mathrm{H}_{21}$ and for a mature particle is $\mathrm{C}_{54} \mathrm{H}_{18}$ (circumcoronene) [40].

The purpose of this paper is to estimate the size of aggregating $^{1}$ aromatics in soot particles. A combination of two techniques is used to find

\footnotetext{
${ }^{1}$ Aggregates are defined as assemblages of PAHs including primary particles. Agglomerates are defined as assemblages of primary particles into fractal structures [41]
} 
characteristic lengths of PAHs: an optical band gap (OBG) determination from Tauc/Davis-Mott analysis [42] to estimate the conjugation length, and 'lattice-fringe' analysis from HRTEM images to estimate fringe lengths. We compare the results of the two techniques from soot formed in a wick-fed diffusion flame burning different liquid fuels. The fuels studied were heptane, toluene and their iso-volumetric mixture (H50T50), given their relevance as surrogate fuels. Extinction measurements were used to calculate the soot volume fraction, $F_{v}$, and determine the OBG. Soot was thermophoretically sampled from the flames and imaged with HRTEM.

\section{Methods}

\subsection{Burner}

In this study, the smoke point test burner [3] was used as simple, known and standardised way to test different liquid fuels in terms of their combustion at atmospheric conditions. This wick-fed burner (inset Figure 1), that has been previously described $[43,44]$, was used to generate a laminar diffusion flame of liquid fuel. The burner consists of a cylindrical reservoir, with an inner concentric hole where the wick is placed, and a $7 \mathrm{~mm}$ i.d nozzle. The flame height is adjusted by rotating a threaded fitting and increasing the wick exposure (i.e, increasing the fuel flow rate).

The fuels tested are heptane, toluene and their mixture of $50 / 50 \%$ by volume (H50T50). Flame heights close to the smoke point were selected: $4 \mathrm{~cm}, 0.7 \mathrm{~cm}$ and $1.1 \mathrm{~cm}$ respectively. In the case of heptane the selected flame height was much lower than its smoke point $(7.3 \mathrm{~cm})$ due to experimental limitations [44]. 


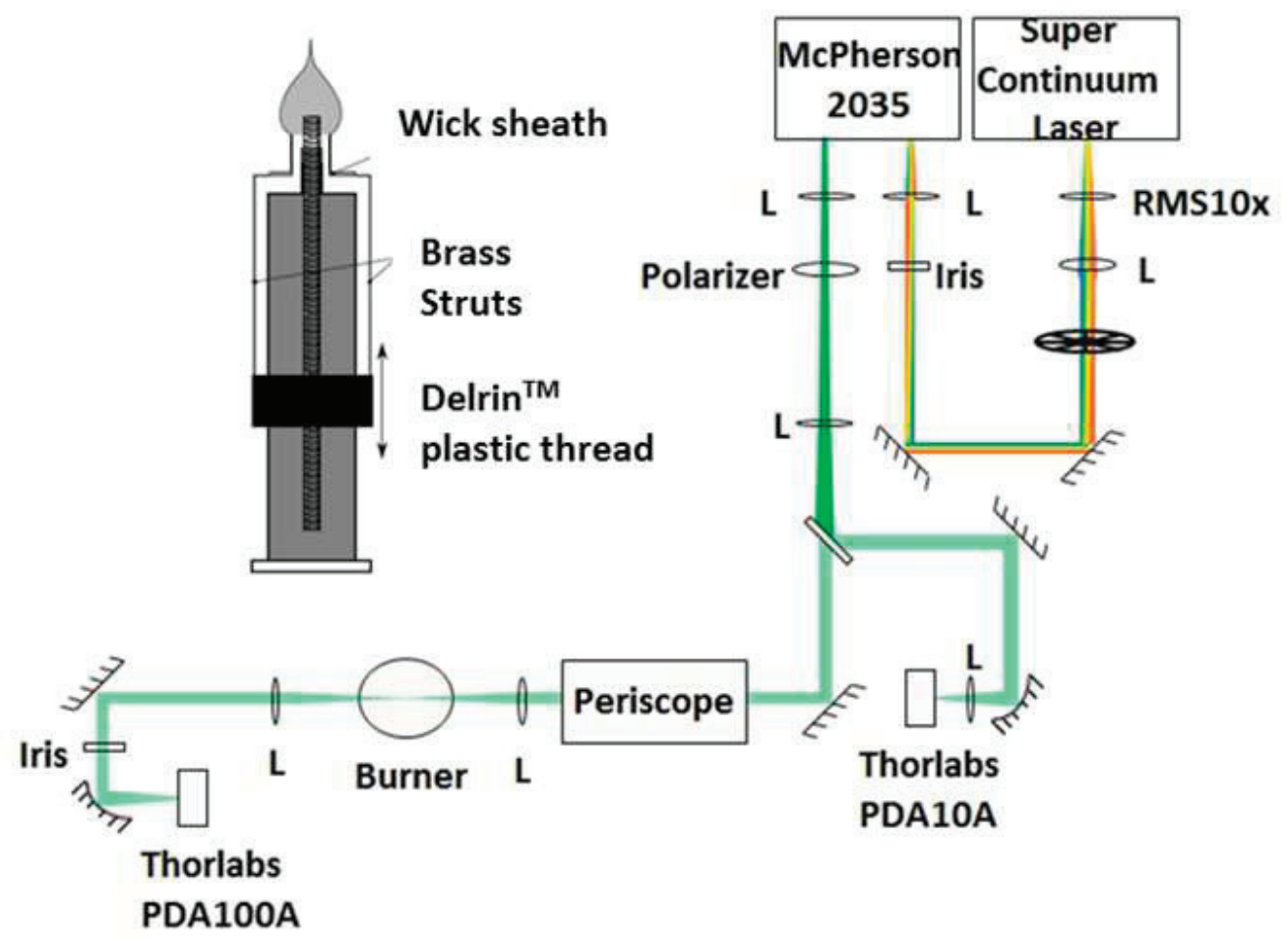

Figure 1: Experimental schematic of line of sight extinction measurements (inset burner schematics). 


\subsection{Extinction Measurements and Tauc analysis}

The experiment schematic is shown in Figure 1. Full details of this setup can be found in a previous manuscript [42]. In summary, the collimated beam from a broadband super continuum light source (NKT Photonics EXB4) was expanded and focused onto the entrance slit of a monochromator, McPherson Model 2035 with $1200 \mathrm{~g} / \mathrm{mm}$ gratings blazed at $500 \mathrm{~nm}$ (providing $2 \mathrm{~nm}$ resolution in the experimental configuration). The beam was then split into two channels, the extinction channel, which provided line of sight measurements through the flame and a power metering channel, which bypasses the flame allowing for power fluctuation monitoring. The transmitted light channel was periscoped into the flame and then focused into the centre of the flame, at the focal point the beam diameter was $0.47 \mathrm{~mm}$. Downstream of the flame, the beam was collimated and focused onto a photodiode detector with a mounted diffuser facilitating detection. A pair of lock-in amplifiers, referencing a chopper at $400 \mathrm{~Hz}$, were used to collect and digitise the signal.

The flame was scanned horizontally over the range $-1.0 \mathrm{~cm}$ to $1.0 \mathrm{~cm}$ in $0.05 \mathrm{~cm}$ increments, at each wavelength. After completing the scan, the positioner would return to the starting position and the monochromator would move $2 \mathrm{~nm}$ to the next wavelength. The procedure was repeated until the entire spectral range, $440 \mathrm{~nm}$ to $740 \mathrm{~nm}$, was covered. The spectral range between $540 \mathrm{~nm}$ and $740 \mathrm{~nm}$ was covered with steps of $10 \mathrm{~nm}$. The height above the burner (HAB) was measured from the burner rim. Heptane flame was mapped from a HAB of $0.5 \mathrm{~cm}$ in $0.5 \mathrm{~cm}$ increments until the tip $(4 \mathrm{~cm})$. H50T50 and toluene flames were mapped from $0.3 \mathrm{~cm} \mathrm{HAB}$, in increments 
of $0.2 \mathrm{~cm}$ until the flame tip $(1.1 \mathrm{~cm}$ and $0.7 \mathrm{~cm}$ respectively).

Given that the flame is axi-symmetric, the line of sight extinction will be a combination of contributions from the different radial positions. The radially distributed extinction was tomographically reconstructed using an Abel inversion technique. In this work, the extinction spectra as a function of wavelength are fit to a power function (which is consistent with Angstrom coefficient analysis of soot particles [45]) prior to tomographic reconstruction to prevent degradation in the signal-to-noise ratio. Fitting the spectra prior to inversion also allows for the quantification of the noise in such a way that the error can be propagated to determine the uncertainty this noise causes in the OBG determination. In addition to quantifying the noise in the data set, the uncertainty is quantified by calculating the deviation in replicate experiments at HAB $2 \mathrm{~cm}, 0.7 \mathrm{~cm}$ and $0.5 \mathrm{~cm}$ for heptane, H50T50 and toluene experiments, respectively. The reported error in the $\mathrm{OBG}$ is the sum of the uncertainty from calculating the extinction on replicate runs and the error propagated from the exponential fit. The light extinction spectra at the flame centerline and light extinction profiles at $500 \mathrm{~nm}$ at different flame heights for the three flames can be found in the Supplementary material.

\subsection{HRTEM and fringe-lattice analysis}

Soot particles are driven thermophoretically to the cold wall of the probe and are ultimately captured on its surface [46]. A fast insertion technique is used to protect the grid from thermal damage [47]. The soot particles were collected in holey carbon films on 300 mesh copper grids. Samples were collected at different position in the flames. Heptane flame was sampled along the centerline at $1 \mathrm{~cm}, 2 \mathrm{~cm}, 3 \mathrm{~cm}$, and $4 \mathrm{~cm} \mathrm{HAB}$, and at the flame 
front at $1 \mathrm{~cm}$ and $2 \mathrm{~cm} \mathrm{HAB}$. Due to the small size of H50T50 and toluene flames, samples were taken at only at the centerline at $0.7 \mathrm{~cm}$ and $1.1 \mathrm{~cm}$ $\mathrm{HAB}$ and $0.7 \mathrm{~cm} \mathrm{HAB}$, respectively.

TEM images were taken using a JEOL 3011 microscope with a specified point-to-point resolution of $0.17 \mathrm{~nm}$. The operating voltage of the microscope is $300 \mathrm{keV}$ using a Lab6 filament. Gatan image software v.3.4 was used for microscope operation. At least 10 images acquired in different regions of the grid (5-10 squares surrounding the grid centre) obtained at different magnifications (500,000 and 600,000) were selected for image analysis.

The HRTEM image analysis algorithm used here was developed and implemented using MATLAB (The Math Works Inc., Natick, MA) based on literature approaches [48], without relying upon commercial image processing packages with unknown preset parameters. A full description of the algorithm can be found in [49]. In general, the background noise is filtered at the Fourier transform level using different bandpass filters. Then the image is transformed from greyscale to binary image using an intensity threshold. The selection of an appropriate threshold is crucial, given that a lot of information can be lost or distorted in this step. Once the binary image is obtained a thinning process called "skeletonisation" is applied, consisting of the conversion of the fringes into thin lines of 1 pixel wide. The skeletonised pixel-based image is first transformed into a vectorial image and then each fringe can be analysed individually in relation to its neighbours.

The "lattice-fringe" analysis performed in this paper contains the following steps for image processing: 1- Region of interest selection, 2- Contrast enhancement using histogram equalisation (discrete gray levels: 5), 3- Gaus- 
sian low-pass filter (size 7, sigma 2), 4- Bottom-hat transformation (disk, size 2), 5- Binarization using Otsu's method, 6- Skeletonisation, 7- Elimination of isolated pixels and pixels with more than 3 connections.

Once the skeleton of the binary image is defined, the connectivity of all pixels is obtained. All connected pixels are detected and stored representing the fringes. The fringe length is then calculated as the Euclidean distance between the fringe pixels. All fringes shorter than $0.483 \mathrm{~nm}$ (two aromatic rings) are eliminated as they are non-physical. Due to image manipulation some information can be lost or modified. For example, branched fringes were artificially separated such that they were individual, this could cause a reduction in the length values determined.

\section{Results and Discussion}

\subsection{Flames description}

The smoke point, defined as the 'maximum height (mm) of a smokeless flame of fuel burned in a wick-fed lamp', indicates the sooting propensity of a fuel. Heptane has the largest smoke point $(\sim 7.3 \mathrm{~cm})$, which indicates a lower sooting tendency. Toluene exhibits the smallest smoke point $(\sim 0.8 \mathrm{~cm})$, hence the higher sooting tendency; H50T50 present an intermediate smoke point $(\sim 1.2 \mathrm{~cm})$. This quantity allows establishing the sooting stage of the studied flames. Toluene and H50T50 flames are close to the smoke point, whereas heptane is well considerably below it (due to apparatus limitations). This should be taken into account when comparing the concentration of soot between the flames. The large difference in the sooting characteristics of the fuels affects as well the flames structure; the maximum heights that can be 
achieved before emitting soot are very different. Toluene's flame is particularly small, which limited the sampling positions for both laser diagnostics and HRTEM. The temperature profiles in such flames are also different. The maximum temperatures in the centreline of the flames (measured with an R-type thermocouple and corrected for thermocouple radiation losses as reported in [50]) are $1770 \mathrm{~K}$ for heptane, $1460 \mathrm{~K}$ for H50T50 and $1410 \mathrm{~K}$ for toluene (with an error of $40 \mathrm{~K}$ ). These differences should influence both soot formation an oxidation having an impact on the final particle concentration and nanostructure.

\subsection{Soot volume fraction $\left(F_{v}\right)$}

The large difference in sooting tendency between toluene and heptane flames can be quantified through Equation 1, which calculates the $F_{v}$, from the experimentally determined radially distributed extinction profile $\left(I / I_{0}\right)$ $[51]$.

$$
F_{v}=\frac{-\ln \left(\frac{I}{I_{0}}\right) \lambda}{l K_{e}}
$$

where $l$ is the path length (tomographic reconstruction step size, $0.05 \mathrm{~cm}$, for this application), $\lambda$ is the wavelength of light, and $K_{e}$ is the dimensionless extinction coefficient of soot. The value for the dimensionless extinction coefficient of soot has been studied and characterised in a variety of fuel systems [52, 53, 54]. Krishnan et al. studied the effect of liquid and gaseous fuels across a range of molecular weights on $K_{e}$ finding a relatively consistent value of $8.6 \pm 1.5$ at $514.5 \mathrm{~nm}$, which is used in this work [53]. The errors in reported $F_{v}$ measurements are calculated from the uncertainty in replicate 
extinction measurements, but the uncertainty in $K_{e}$ value results in a $17 \%$ error intrinsic to reported $F_{v}$ values, and additional error maybe introduced through the wavelength dependence of $K_{e}[53]$.

Figure 2 presents an image of the calculated $F_{v}$ for the heptane, H50T50 and toluene flames measured at $540 \mathrm{~nm}$. In the heptane flame particle concentrations were not observable until $1 \mathrm{~cm} \mathrm{HAB}$ (in the wings) and $2.5 \mathrm{~cm}$ $\mathrm{HAB}$ (along the centerline) and maximum soot concentrations are found in the centre of the flame. As toluene is added the maximum concentration migrates from the centre to the wings, a similar trend has been observed in other highly sooting flames [42]. The maximum $F_{v}$ concentration in H50T50 and toluene flames exceed the maximum $F_{v}$ in heptane flames by a factor of four.

\section{3. $O B G$ calculation}

In the late 1960's and early 1970's, two groups (Tauc and Davis/Mott) demonstrated that the long wavelength edge of the optical absorption of amorphous semiconductors acts as a probe of the localised states [55, 56]. Therefore the optical band gap (OBG) can be calculated from Equation 2.

$$
h \nu \cdot \alpha \approx(h \nu-O B G)^{r}
$$

where $\alpha$ is the extinction coefficient and $r$ is a constant describing the directness and quantum mechanical allowedness of the optical transition. In this work a value of $r=1 / 2$ is used corresponding to a direct allowed transition $[57,58]$. In the work conducted by D'Alessio et al. of extinction spectra $[59,60,61,62]$ and subsequent work of UV-Vis spectra from collaborating 


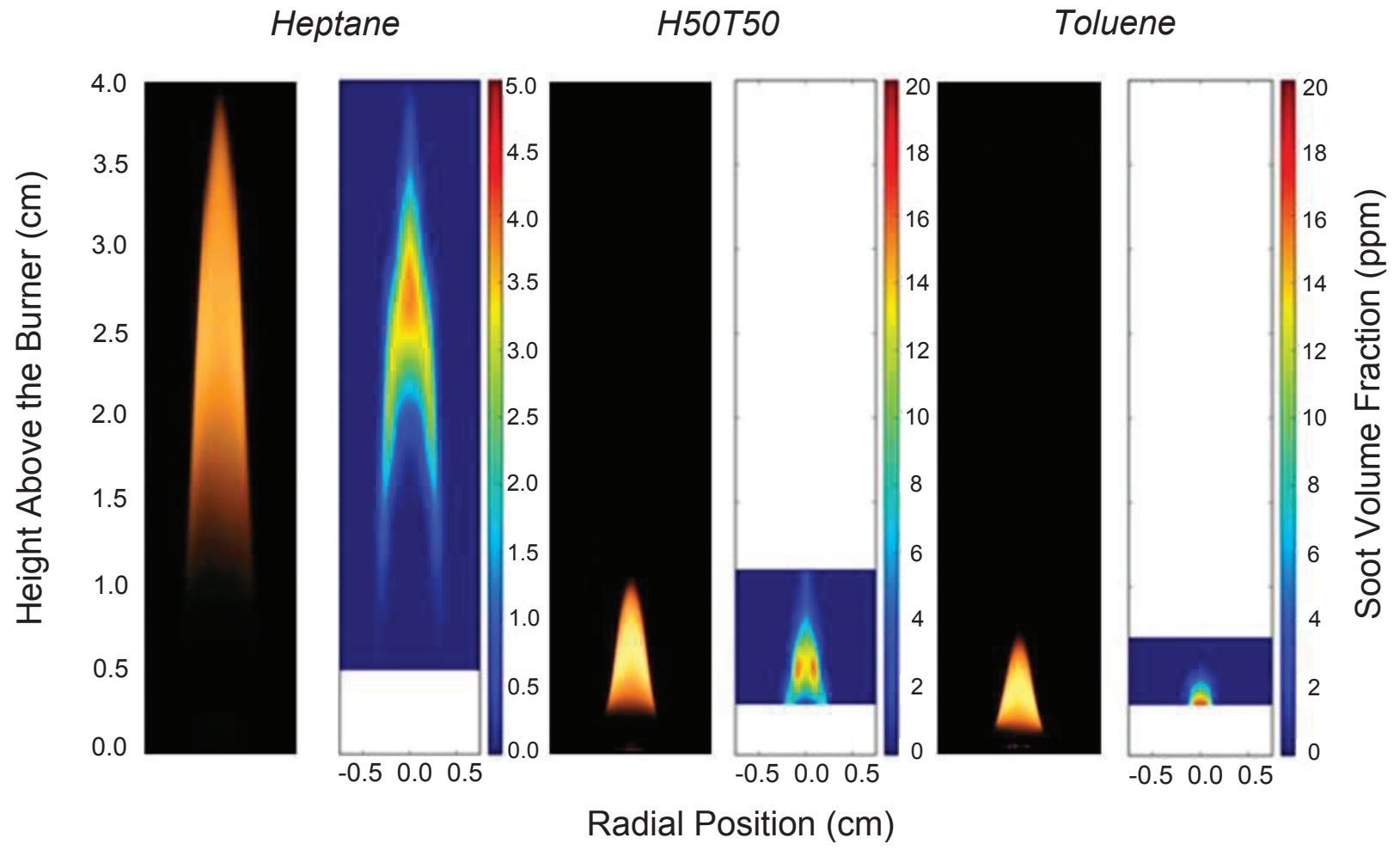

Figure 2: $F_{v}$ as calculated from extinction measurements at $540 \mathrm{~nm}$ (image on the right of each pair). Flame photo (image on the left of each pair). Heptane flame: peak $F_{v}$ $3.4 \mathrm{ppm} \pm 0.5 \mathrm{ppm}$; H50T50 flame: peak $F_{v} 14.9 \mathrm{ppm} \pm 2.7 \mathrm{ppm}$; Toluene flame: peak $F_{v} 17.6 \mathrm{ppm} \pm 0.6 \mathrm{ppm}$.

groups $[63,64,65]$ an $r$ value of 2 corresponding to a nondirect transition in an amorphous semi-conductor (same $r$ value as an indirect allowed transition that are used for crystalline materials) has been used along with a multiple band gap fitting approach. These studies of the optical band gap provided insight into trends regarding the relationship between electronic properties and flame structure. However, when using the Tauc analysis with an $r$ value of 2 , there have been issues reported in the literature with correlating the experimentally determined optical band gaps with molecular size [66, 67, 68]. In 
the next section we will present TD-DFT calculation, that correlates molecular size with computed HOMO-LUMO gaps in a series of PAH by optimizing the ground state geometry and then computing the excited state energies (assuming the same geometry). In this case, the computed gaps correspond to vertical or direct transitions. In our Tauc/Davis-Mott analysis, while using $r=2$ generated a linear portion of the Tauc plot (generally an indication of being an appropriate application of the $\mathrm{r}$ value), when mapping out the entire flames not only was it necessary to extrapolate several eV to the apparent $E_{g}$ (which leads to large uncertainties), but more importantly optical band gaps were obtained that were nonphysical and others that correlated with molecular sizes that were orders of magnitude larger than seemed plausible. Because the approach we adopted and results obtained for the relationship between molecular size and optical band gap were in line with the literature $[69,70,71]$, we began to question the assumption of the $r=2$ value used in Tauc analysis. In our view, at the molecular level, PAH and nascent soot particles are viewed as analogues of finite graphene sheets [72], which have direct optical band gaps $[69,73,74]$ and not amorphous carbon structures with substantially higher $\mathrm{sp}^{3}$ carbon character and higher hydrogen content, for which Robertson initially applied the Tauc relationship. Therefore, in our analysis we use $r=1 / 2$ corresponding to a direct optical band gap. However, we have included figures in the Supplementary material for comparison between the traditional Tauc method and the one utilized here.

To determine the OBG, $(h \nu \cdot \alpha)^{1 / r}$ was plotted as a function of photon energy $(\mathrm{eV})$, and the straight line portion (determined in previous publications to be over the spectral range from $440 \mathrm{~nm}$ to $540 \mathrm{~nm}$ [42]) of the plot was 
extrapolated to the $x$-intercept. Examples of these plots can be found in the Supplementary material. This procedure was repeated at each height and radial position, only using position data where the linear portion possessed an $R^{2}$ greater than 0.9 and where the power fit noise was less than $50 \%$. A consequence of treating the $\mathrm{OBG}$ as a direct transition is that the curvature observed by approaching the OBG (Urbach occurrence) is shifted from the visible NIR region, as observed when $r=2$, into the visible. The shift of the OBG into the visible when analysing the optical transitions as direct, means that we need to exclude wavelengths above the point where linearity is lost, which was determined to be $540 \mathrm{~nm}$ in our previous paper [42]. Because of this and the goal of comparing experimentally measured direct transitions and computed ones, we have not adopted the use of the multiple band gap fitting approach for this applications [60].

Figure 3 presents the calculated $\mathrm{OBG}$ and $F_{v}$ for the three studied flames. In the heptane flame (Figure 3a) it can be observed that at low $\mathrm{HAB}, \mathrm{OBG}$ is lower close to the flame front, where there is the largest concentration of soot. Moving downstream, lower values of $\mathrm{OBG}$ are found close to the flame centerline, at the flame tip the OBG increases again possibly due to soot oxidation. The same behaviour is observed in H50T50 and toluene flames (Figures 3c,3e). Oxidation at the tip has been observed in similar flame systems using different diagnostics $[44,50]$.

\subsection{Correlating OBG measurements to molecular size}

Robertson and Ferrari showed that systems with $\mathrm{sp}^{2}$ character, such as soot, have electronic properties that are dominated by $\pi-\pi^{*}$ interactions $[75,76]$. Based on these conclusions, they showed the OBG scales inversely 


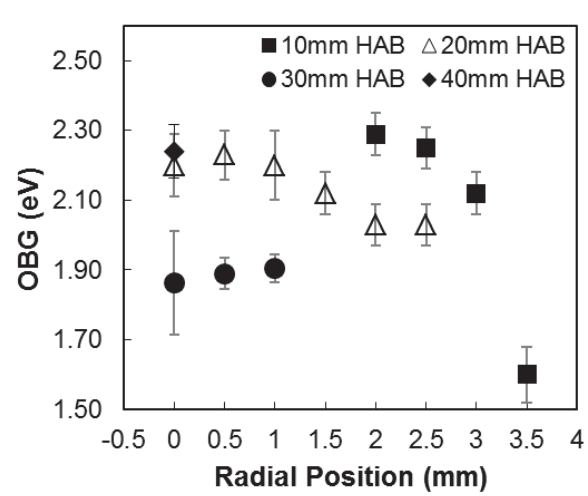

(a) Heptane OBG

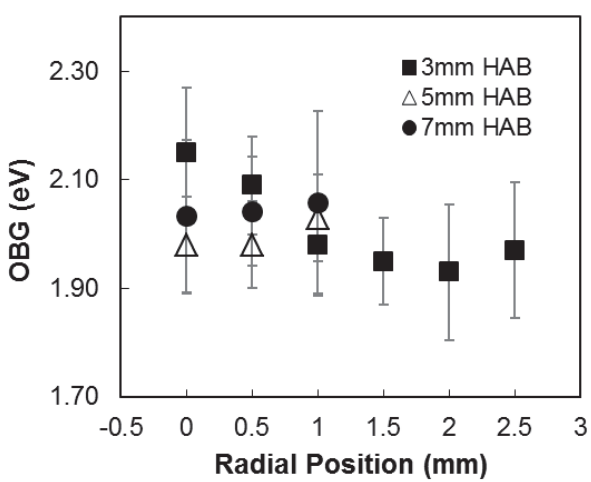

(c) H50T50 OBG

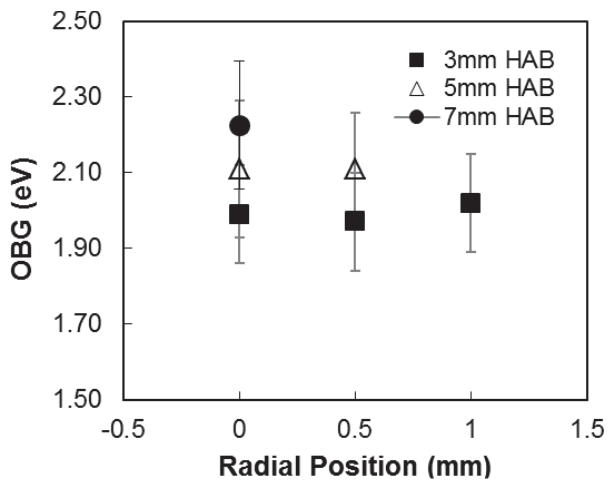

(e) Toluene OBG

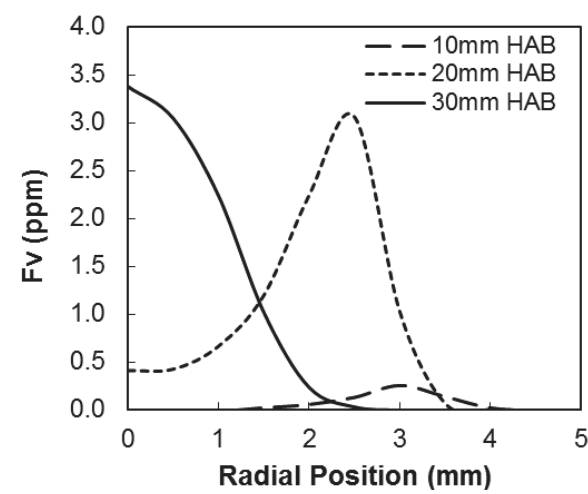

(b) Heptane soot volume fraction

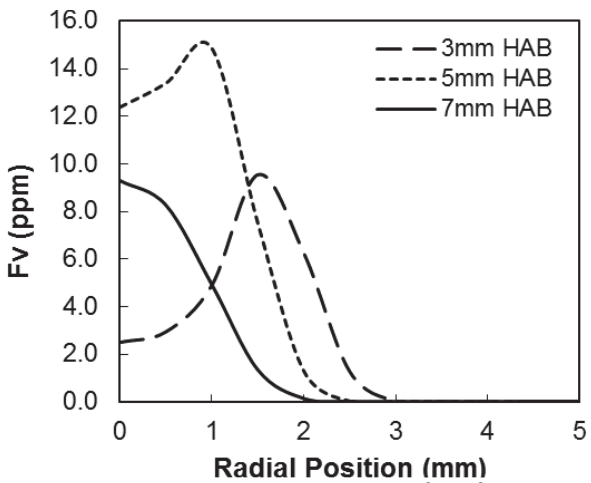

(d) H50T50 soot volume fraction

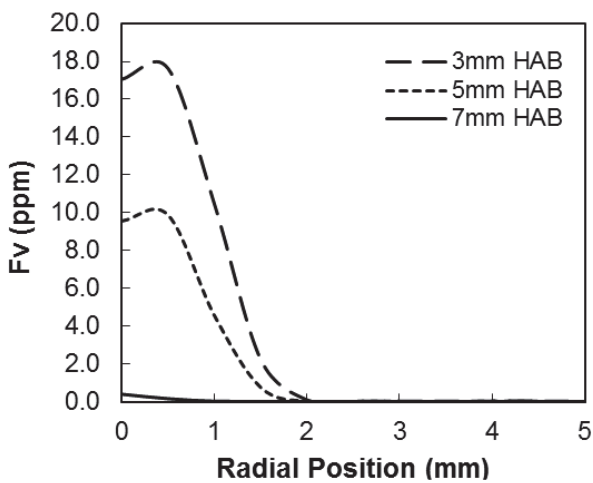

(f) Toluene soot volume fraction

17

Figure 3: Experimentally determined $\mathrm{OBG}$ and soot volume fraction as a function of radial position and height above the burner for the a,b) heptane flame, c,d) 50\% heptane-50\% toluene flame and e,f) toluene flame 
with the size of the pericondensed aromatic structure [77, 78, 79]. Using this relationship, Miller et al. related computational results of the calculated HOMO-LUMO gaps for a variety of $D_{2 h}$ PAH molecules to the number of aromatic rings in the structure resulting in the following relationship (Equation 3):

$$
O B G=\frac{5.8076}{M^{1 / 2}}+0.5413=\frac{1.4787}{L_{a}}+0.5413
$$

where $\mathrm{M}$ is the number of aromatic rings and $L_{a}$ is the conjugation length $[75,76]$. In different techniques various titles for the variable $L_{a}$ have been used including "in-plane crystallite size", "correlation length", and "conjugation length". All of these descriptors address the same concept of the characteristic dimension of a planar $\pi$ system. Equation 3 relates the experimentally determined OBG to the physical size of the PAH [80]. A plot combining the relationship between the number of aromatic rings and the OBG and the relationship between the number of aromatic rings and the conjugation length is presented in the Supplementary material.

Throughout the flame systems we observe a fairly consistent range of OBG values in the range of $1.73-2.39 \mathrm{eV}$ (and thus estimated size of PAH of 10-20 rings). The average OBG for the flame systems were $2.07 \mathrm{eV}, 2.04 \mathrm{eV}$, and $2.10 \mathrm{eV}$ for the n-heptane flame, H50T50 flame, and toluene flame, respectively (full summary in Table 1). These values correspond to an average PAH size between 15-16 aromatic rings, about the size of circumpyrene ( 520 u). Interestingly, the H50T50 flame has an average OBG lower than either of the component compounds. However, the range in the OBG reported in all flame systems are all within the uncertainty in the measurements. 
The results from Tauc/Davis-Mott analysis are more qualitative than quantitative, in that assumptions about the type of transitions affect the optical band gaps obtained. The method itself is more sensitive to the larger structures because of the dependence on the near edge of the absorption feature. Additionally, the estimation of OBG as the HOMO-LUMO gaps of single PAHs is a simplified view of a complex aggregated system. As the PAHs aggregate to form dimers the increase in the density of states around the HOMO-LUMO gap results in a slightly lower OBG, the literature suggests that the initial dimerization lowers the band gap, but subsequent layers have little effect [81]. Lastly, the relation between OBG and molecular

size $[75,76]$ assumes planar pericondensed aromatic structures, meaning that the analysis is limited to 6 -membered rings. It is because of these limitations that the analysis is strengthened by combining it with HRTEM, which allows for a measure of stacking, fringe length, and curvature.

\subsection{Fringe length calculation}

Figure 4 show representative HRTEM images of samples taken at the tip of each flame $(4 \mathrm{~cm} \mathrm{HAB}$ for heptane, $1.1 \mathrm{~cm} \mathrm{HAB}$ for H50T50 and $0.7 \mathrm{~cm}$ HAB for toluene). The corresponding image analysis mapping all relevant fringes are presented in the bottom row. An 'onion-like' distribution of the fringes is observed, showing nearly spherical primary particles of different sizes stick to each other. Qualitatively heptane's soot seems to have shorter and more curved fringes compared to H50T50 and toluene, indicating a lower degree of graphitisation.

From the lattice-fringe analysis a fringe length distribution is obtained. The mean fringe length calculated at all sampling points for the three flames 

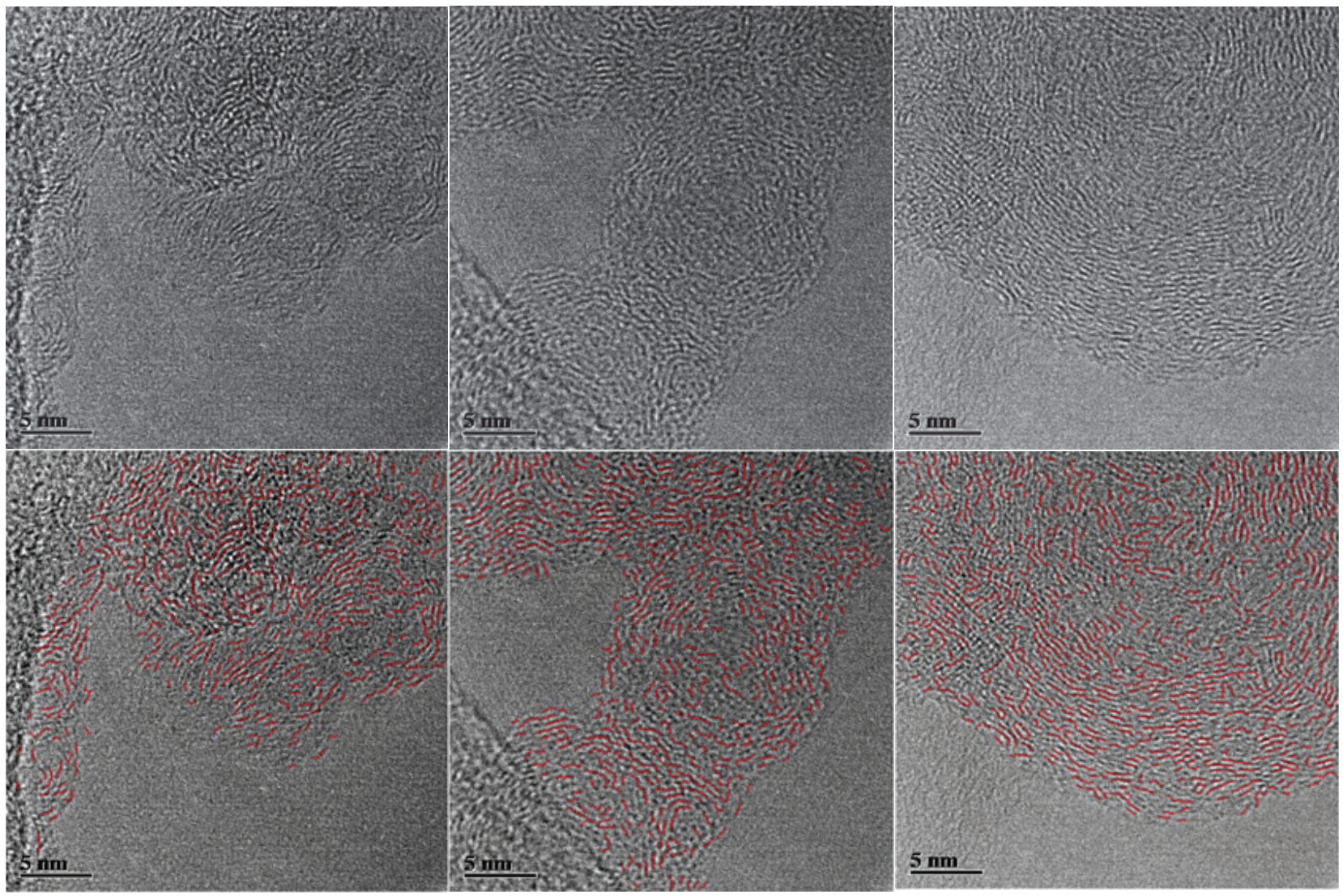

Figure 4: HRTEM images taken at magnification 600,000x, sampled at the tip of the flames. Left: Heptane Flame, Centre: H50T50 Flame, Right: Toluene Flame. Top row corresponds to raw image and bottom row contains overlaid fringe mapping.

is presented in Figure 5. Results show that the fringe length increases with HAB in the heptane flame, until a point after which it decreases considerably. Previous measurements of soot particle size [44] indicate that oxidation plays a large role and that could explain the smaller length of the PAHs. There is not a significant difference in the mean fringe length obtained in the centerline and the wing at the same HAB. For H50T50, the mean fringe length decreases from $0.7 \mathrm{~cm}$ to $1.1 \mathrm{~cm}$ HAB, possibly due to oxidation at the flame tip. 
Toluene was only sampled at the tip and exhibited the highest values of fringe length.

Fringe lengths obtained from HRTEM images represent only graphitic sheets parallel to the beam and do not provide any information on the 2-D structure of the PAH. Additionally the quality of the image is important for the final result. Although the quality of the HRTEM as displayed in Figure 4 is reasonable, there is still a considerable uncertainty associated with the fringe length analysis. However, it is encouraging that the fringe length estimated from the OBG measurements are of similar size.

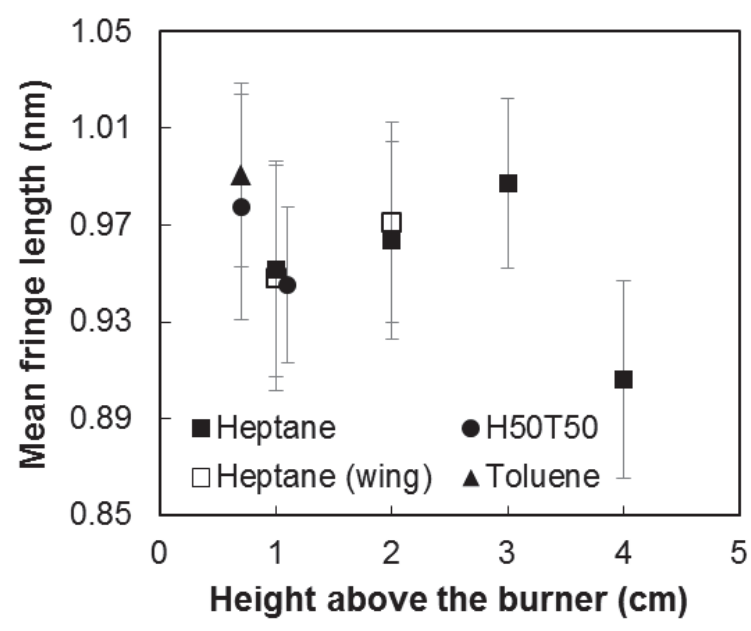

Figure 5: Mean fringe length values calculated from HRTEM images and fringe lattice analysis. Only the heptane flame was sampled at position different than the centerline corresponding to empty symbols. The flame heights are $4 \mathrm{~cm}$ for Heptane, $1.1 \mathrm{~cm}$ for H50T50 and $0.7 \mathrm{~cm}$ for Toluene. 


\subsection{Comparison of fringe and conjugation length}

Table 1 presents the comparison between values of fringe and conjugation lengths, which are both measures of the typical length scale of a PAH. For all fuels the values obtained with the two experimental methodologies are very consistent. All observed differences between fuels are well within the experimental uncertainty for both conjugation and fringe length results. While the $F_{v}$ and flame structure vary tremendously between the toluene, heptane, and H5050 flames, the conjugation and fringe lengths do not. This suggests that there is commonality during the nucleation process (aggregation), but variation in agglomeration.

The results obtained are in agreement with recent studies of conjugation length from both OBG determination and Raman [27] studies conducted using an ethylene-diluted co-flow diffusion flame, where results indicated PAH species with conjugation lengths between $0.81 \mathrm{~nm}$ to $1.13 \mathrm{~nm}$ and $1.0 \mathrm{~nm}$ to $1.2 \mathrm{~nm}$, respectively [27, 42]. Similarly, a recent publication of HRTEM in an ethylene flame reports fringe length measurements in the range from $0.94 \mathrm{~nm}$ to $1.24 \mathrm{~nm}$ and conjugation lengths from Raman studies from $1.03 \mathrm{~nm}$ to $1.13 \mathrm{~nm}[82]$. In computational studies we have found a critical size of pericondensed PAH for mature soot particles in the range of circumcoronene (conjugation length about $1.11 \mathrm{~nm}$ ) [40].

\section{Conclusions}

Analysis of extinction measurements and HRTEM was used to estimate the length of molecules that constitute soot particles formed in wick-fed diffusion flames of heptane, toluene and its iso-volumetric mixture. The two 
Table 1: Comparison of the range of OBG, conjugation length and fringe length observed across all flame systems.

\begin{tabular}{lcccccccccccccc}
\hline & \multicolumn{3}{c}{ OBG $(\mathrm{eV})$} & \multicolumn{3}{c}{$\begin{array}{c}\text { Number of aromatic } \\
\text { rings }\end{array}$} & \multicolumn{2}{c}{$\begin{array}{c}\text { Conjugation Length } \\
(\mathrm{nm})\end{array}$} & \multicolumn{3}{c}{$\begin{array}{c}\text { Mean fringe length } \\
(\mathrm{nm})\end{array}$} \\
\hline Flame & Min. & Max. & Mean & Min. & Max. & Mean & Min. & Max. & Mean & Min. & Max. & Mean \\
\hline Heptane & 1.75 & 2.38 & 2.07 & 9.98 & 23.1 & 14.4 & 0.80 & 1.22 & 0.97 & 0.91 & 0.99 & 0.95 \\
H50T50 & 1.93 & 2.16 & 2.04 & 12.8 & 17.5 & 15.0 & 0.91 & 1.12 & 0.99 & 0.95 & 0.98 & 0.97 \\
Toluene & 1.73 & 2.29 & 2.10 & 11.0 & 23.9 & 13.9 & 0.85 & 1.24 & 0.97 & 0.99 & 0.99 & 0.99 \\
\hline
\end{tabular}

estimators are conjugation length obtained from extinction measurements and fringe length derived from HRTEM images. The tomographically reconstructed extinction data was processed using Tauc/Davis-Mott analysis to determine the optical band gap. A direct band gap was selected for this analysis assuming that the electronic properties of soot are dominated by the molecular structure of the PAHs, and for correlation with HOMO-LUMO gaps for PAHs. The OBG ranges from about $1.73 \mathrm{eV}$ to $2.39 \mathrm{eV}$ were measured in the flames correlating to an average size of a structure with 15 aromatic rings. Average PAH sizes in the three flames correspond to conjugation lengths around $1 \mathrm{~nm}$. Similar sizes were obtained using fringe-lattice analysis of HRTEM images taken from soot thermophoretically sampled in the same flames. Mean fringe lengths between $0.95 \mathrm{~nm}$ and $0.99 \mathrm{~nm}$ were estimated. The results suggest that flames of different fuel nature and sooting stage undergo the transition from chemical to physical growth at a similar size, about the size of circumpyrene. 


\section{Acknowledgments}

The authors gratefully acknowledge partial funding by the Royal Society, grant IE120400. This project was partly funded by the National Research Foundation (NRF), Prime Minister's Office, Singapore under its Campus for Research Excellence and Technological Enterprise (CREATE) programme. M.B acknowledges financial support provided by the Administrative Department of Science, Technology and Innovation of Colombia. The GWU portion of this work was supported in part by the U.S. National Science Foundation under grants CBET-0828950 and CBET-1142284 with Drs Philip Westmoreland, Avind Atreya, and Ruey-Hung Chen serving as technical monitors.

\section{References}

\section{References}

[1] W. Pitz, N. Cernansky, F. Dryer, F. Egolfopoulos, J. T. Farrell, D. G. Friend, H. Pitsch, SAE technical paper (2007).

[2] J. T. Farrell, N. Cernansky, F. Dryer, C. K. Law, D. G. Friend, C. Hergart, R. M. McDavid, A. K. Patel, C. J. Mueller, H. Pitsch, SAE technical paper (2007).

[3] ASTM, ASTM Standard D1322-08 (1997).

[4] R. A. Hunt, Industrial and Engineering Chemistry 45 (1953) 602-606.

[5] R. Schalla, G. McDonald, Industrial and Chemical Chemistry 45 (1953) $1497-1500$. 
[6] A. Hamins, D. T. Anderson, J. Houston Miller, Combustion Science and Technology 71 (1990) 175-195.

[7] H. F. Calcote, D. M. Manos, Combustion and Flame 49 (1983) 289-304.

[8] M. Frenklach, H. Wang, Symposium (International) on Combustion 23 (1991) 1559 - 1566. Twenty-Third Symposium (International) on Combustion.

[9] P. Mitchell, M. Frenklach, Symposium (International) on Combustion 27 (1998) 1507 - 1514. Twenty-Seventh Sysposium (International) on Combustion Volume One.

[10] M. Frenklach, Physical Chemistry Chemical Physics 4 (2002) 2028-2037.

[11] H. Richter, J. Howard, Progress in Energy and Combustion Science 26 (2000) $565-608$.

[12] M. Celnik, A. Raj, R. West, R. Patterson, M. Kraft, Combustion and Flame 155 (2008) 161 - 180.

[13] A. Raj, M. Celnik, R. Shirley, M. Sander, R. Patterson, R. West, M. Kraft, Combustion and Flame 156 (2009) 896 - 913.

[14] S. Mosbach, M. S. Celnik, A. Raj, M. Kraft, H. R. Zhang, S. Kubo, K.-O. Kim, Combustion and Flame 156 (2009) 1156 - 1165.

[15] T. S. Totton, D. Chakrabarti, A. J. Misquitta, M. Sander, D. J. Wales, M. Kraft, Combustion and Flame 157 (2010) 909 - 914. 
[16] J. Appel, H. Bockhorn, M. Frenklach, Combustion and Flame 121 (2000) $122-136$.

[17] H. Wang, Proceedings of the Combustion Institute 33 (2011) 41 - 67.

[18] R. Dobbins, R. Fletcher, H.-C. Chang, Combustion and Flame 115 (1998) $285-298$.

[19] M. Commodo, G. Tessitore, G. D. Falco, A. Bruno, P. Minutolo, A. DAnna, Proceedings of the Combustion Institute 35 (2015) 1795 1802.

[20] J. H. Miller, Proceedings of the Combustion Institute 30 (2005) 1381 1388.

[21] H. Chen, R. Dobbins, Combustion Science and Technology 159 (2000) $109-128$.

[22] R. L. V. Wal, Combustion Science and Technology 126 (1997) 333-351.

[23] R. L. V. Wal, Combustion Science and Technology 132 (1998) 315-323.

[24] T. Ishiguro, Y. Takatori, K. Akihama, Combustion and Flame 108 (1997) $231-234$.

[25] M. Alfe, B. Apicella, R. Barbella, J.-N. Rouzaud, A. Tregrossi, A. Ciajolo, Proceedings of the Combustion Institute 32 (2009) 697 - 704 .

[26] M. Alfe, B. Apicella, J.-N. Rouzaud, A. Tregrossi, A. Ciajolo, Combustion and Flame 157 (2010) 1959 - 1965. 
[27] J. D. Herdman, B. C. Connelly, M. D. Smooke, M. B. Long, J. H. Miller, Carbon 49 (2011) 5298 - 5311.

[28] J. Singh, M. Balthasar, M. Kraft, W. Wagner, Proceedings of the Combustion Institute 30 (2005) 1457 - 1465.

[29] M. Celnik, R. Patterson, M. Kraft, W. Wagner, Combustion and Flame 148 (2007) $158-176$.

[30] C. A. Schuetz, M. Frenklach, Proceedings of the Combustion Institute 29 (2002) $2307-2314$.

[31] J. Happold, H.-H. Grotheer, M. Aigner, Rapid Communications in Mass Spectrometry 21 (2007) 1247-1254.

[32] D. Chen, T. S. Totton, J. Akroyd, S. Mosbach, M. Kraft, Carbon 77 (2014) $25-35$.

[33] D. Chen, T. S. Totton, J. W. Akroyd, S. Mosbach, M. Kraft, Carbon 67 (2014) $79-91$.

[34] P. Elvati, A. Violi, Proceedings of the Combustion Institute 34 (2013) $1837-1843$.

[35] J. S. Lowe, J. Y. Lai, P. Elvati, A. Violi, Proceedings of the Combustion Institute 35 (2015) 1827 - 1832.

[36] A. Raj, M. Sander, V. Janardhanan, M. Kraft, Combustion and Flame 157 (2010) $523-534$. 
[37] M. Sander, R. I. Patterson, A. Braumann, A. Raj, M. Kraft, Proceedings of the Combustion Institute 33 (2011) 675 - 683.

[38] D. Chen, Z. Zainuddin, E. Yapp, J. Akroyd, S. Mosbach, M. Kraft, Proceedings of the Combustion Institute 34 (2013) 1827 - 1835.

[39] M. Frenklach, H. Wang, in: H. Bockhorn (Ed.), Soot Formation in Combustion, volume 59 of Springer Series in Chemical Physics, Springer Berlin Heidelberg, 1994, pp. 165-192.

[40] D. Chen, J. Akroyd, S. Mosbach, D. Opalka, M. Kraft, Combustion and Flame 162 (2015) $486-495$.

[41] G. Nichols, S. Byard, M. J. Bloxham, J. Botterill, N. J. Dawson, A. Dennis, V. Diart, N. C. North, J. D. Sherwood, Journal of Pharmaceutical Sciences 91 (2002) 2103-2109.

[42] E. M. Adkins, J. H. Miller, Physical Chemistry Chemical Physics 17 (2015) 2686-2695.

[43] R. J. Watson, M. L. Botero, C. J. Ness, N. M. Morgan, M. Kraft, Fuel $111(2013) 120-130$.

[44] M. L. Botero, S. Mosbach, M. Kraft, Fuel 126 (2014) 8- 15.

[45] H. Moosmüller, R. K. Chakrabarty, K. M. Ehlers, W. P. Arnott, Atmospheric Chemistry and Physics 11 (2011) 1217-1225.

[46] R. A. Dobbins, C. M. Megaridis, Langmuir 3 (1987) 254-259. 
[47] U. Koylu, C. McEnally, D. Rosner, L. Pfefferle, Combustion and Flame 110 (1997) $494-507$.

[48] K. Yehliu, R. L. V. Wal, A. L. Boehman, Combustion and Flame 158 (2011) $1837-1851$.

[49] M. L. Botero, D. Chen, S. Gonzlez-Calera, D. Jefferson, M. Kraft, Carbon 96 (2016) $459-473$.

[50] M. L. Botero, S. Mosbach, J. Akroyd, M. Kraft, Fuel 153 (2015) 31 39.

[51] H. Zhao, N. Ladommatos, Progress in Energy and Combustion Science 24 (1998) $221-255$.

[52] S. S. Krishnana, K.-C. Lin, G. M. Faeth, Journal of Heat Transfer 123 (2000) 331-339.

[53] S. S. Krishnana, K.-C. Lin, G. M. Faeth, Journal of Heat Transfer 122 (2000) 517-524.

[54] T. Williams, C. Shaddix, K. Jensen, J. Suo-Anttila, International Journal of Heat and Mass Transfer 50 (2007) 1616 - 1630.

[55] J. Tauc, R. Grigorovici, A. Vancu, physica status solidi b 15 (1966) 627-637.

[56] D. L. Wood, J. Tauc, Physics Review B 5 (1972) 3144-3151.

[57] E. A. Davis, N. F. Mott, Philosophical Magazine 22 (1970) 0903-0922. 
[58] K. W. Nevill F. Mott, E. A. Davis, Electronic Processes in NonCrystalline Materials, Oxford University Press, 1971.

[59] A. D'Alessio, G. Gambi, P. Minutolo, S. Russo, A. D'Anna, Symposium (International) on Combustion 25 (1994) 645 - 651. Twenty-Fifth Symposium (International) on Combustion.

[60] P. Minutolo, G. Gambi, A. D'Alessio, Symposium (International) on Combustion 26 (1996) $951-957$.

[61] A. DAlessio, A. DAnna, G. Gambi, P. Minutolo, Journal of Aerosol Science 29 (1998) 397 - 409.

[62] C. Allouis, A. D'Alessio, F. Beretta, A. Borghese, Proceedings of the Combustion Institute 28 (2000) 311 - 317.

[63] A. Ciajolo, B. Apicella, R. Barbella, A. Tregrossi, Combustion Science and Technology 153 (2000) 19-32.

[64] C. Russo, F. Stanzione, A. Ciajolo, A. Tregrossi, Proceedings of the Combustion Institute 34 (2013) 3661 - 3668.

[65] C. Russo, M. Alf, J.-N. Rouzaud, F. Stanzione, A. Tregrossi, A. Ciajolo, Proceedings of the Combustion Institute 34 (2013) 1885 - 1892.

[66] T. C. Bond, Geophysical Research Letters 28 (2001) 4075-4078.

[67] J. Robertson, Materials Science and Engineering: R: Reports 37 (2002) $129-281$. 
[68] I. Llamas-Jansa, C. Jger, H. Mutschke, T. Henning, Carbon 45 (2007) $1542-1557$.

[69] Y.-W. Son, M. L. Cohen, S. G. Louie, Phys. Rev. Lett. 97 (2006) 216803.

[70] Y. Ruiz-Morales, The Journal of Physical Chemistry A 106 (2002) $11283-11308$.

[71] M. Parac, S. Grimme, Chemical Physics 292 (2003) $11-21$.

[72] L. Zhi, K. Mullen, J. Mater. Chem. 18 (2008) 1472-1484.

[73] L. Yang, C.-H. Park, Y.-W. Son, M. L. Cohen, S. G. Louie, Phys. Rev. Lett. 99 (2007) 186801.

[74] G. Gui, J. Li, J. Zhong, Phys. Rev. B 78 (2008) 075435.

[75] J. Robertson, World of Carbon, volume 1, Gordon adn Breach, pp. 249273.

[76] J. Robertson, E. P. O’Reilly, Physics Review B 35 (1987) 2946-2957.

[77] L. G. Cançado, K. Takai, T. Enoki, M. Endo, Y. A. Kim, H. Mizusaki, A. Jorio, L. N. Coelho, R. Magalhes-Paniago, M. A. Pimenta, Applied Physics Letters 88 (2006) - .

[78] A. C. Ferrari, J. Robertson, Physics Review B 61 (2000) 14095-14107.

[79] A. C. Ferrari, J. Robertson, Physics Review B 64 (2001) 075414.

[80] J. H. Miller, J. D. Herdman, C. D. Green, E. M. Webster, Proceedings of the Combustion Institute 34 (2013) 3669 - 3675. 
[81] C. Feng, C. S. Lin, W. Fan, R. Q. Zhang, M. A. Van Hove, The Journal of Chemical Physics 131 (2009) - .

[82] B. Apicella, P. Pre, M. Alfe, A. Ciajolo, V. Gargiulo, C. Russo, A. Tregrossi, D. Deldique, J. Rouzaud, Proceedings of the Combustion Institute 35 (2015) $1895-1902$. 
Supplementary Material
Click here to download S

Click here to download Supplementary Material: WickedFlameDraft_SupplementalRound2_80ct15 (1).docx (1) (1) (1) (1) .

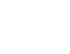
. . . . . . . . . . . 